\title{
The Study on Urban Agglomeration Environmental Rights Trading Paradigm - With the Emission Trading Model of Wan-Jiang City Belt
}

\author{
Xianbiao Wei, Mo Wang, Yuzhen Duan, Xiaobao Peng \\ University of Science and Technology of China, Hefei, China \\ Email:wxb5316@163.com
}

How to cite this paper: Wei, X.B., Wang, M., Duan, Y.Z. and Peng, X.B. (2017) The Study on Urban Agglomeration Environmental Rights Trading Paradigm-With the Emission Trading Model of Wan-Jiang City Belt. Journal of Geoscience and Environment Protection, 5, 296-315.

https://doi.org/10.4236/gep.2017.59020

Received: March 1, 2017

Accepted: September 26, 2017

Published: September 29, 2017

Copyright $\odot 2017$ by authors and Scientific Research Publishing Inc. This work is licensed under the Creative Commons Attribution International License (CC BY 4.0).

http://creativecommons.org/licenses/by/4.0/

(c) (i) Open Access

\begin{abstract}
As the deterioration of the modern environmental problems, developed countries started to explore concrete ways of internalization of external effects produced by environmental problems. The theory of new institutional economics which produced the environmental property theory is widely used in the research of environmental management. On the premise of total amount control of pollution, the subjects of public power distribute or sell the rights is the basic paradigm of this method. Buyers take possession of the rights and utilize, profit from or dispose of them. The coordinated development of urban agglomeration is the main direction of China's regional development strategy. As there are differences in environmental governance in different cities, the environment property trading system of urban agglomeration needs to be established urgently. Due to environmental property's complexity and its attributes of public goods, the transaction of environmental property is restricted by amounts of factors. This research concludes that it is necessary to define the possessor of environmental property, strengthen the construction of trading platform, improving the public participation and supervision mechanism and control transaction cost by establishing and analyzing the emission trading model of the city-cluster along the Yangtze River in Anhui Province.
\end{abstract}

\section{Keywords}

Environmental Property, Urban Agglomeration, Emission Trading

\section{Introduction}

With the establishment of modern environmental protection concept, developed 
countries started to explore the specific methods that are used to internalize the external effects caused by environmental problems. Since the 1970s, new institutional economics theory started to be widely used in the studies on the environmental economy, environmental legislation and environmental management. Environment is economically defined as "public goods" and is not exclusive, so the benefits brought by environmental protection are difficult to exclude the use of the others. Individuals don't need to pay for the environmental damages, thus the economic sense of the negative external effects engenders. However, the scarcity of environmental resources (natural resources and pollutant-holding capacity) cannot be ignored. In contemporary times, with the development of economy and the increase of population, the contradiction between demand and supply of environmental resources is becoming increasingly acute. Environmental resources become rarer, which promotes the clear defining of environmental property. New institutional economics school argues that property rights originate from the scarcity of resources. Property rights origin model of NorthThomas and Harold.Demsetz explains the process of property rights establishment-different people use these rare resources, thus the exclusive interests form, people start to define, use and protect rare resources. With the use of environmental resources, the scarcity of environmental resources becomes more obvious, the concept of environmental property is gradually clear, the theories about distribution, transaction and use of environmental property form. Ronald $\mathrm{H}$. Coase who puts forward the issue of "social costs" first thought that in a world of zero transaction costs, no matter how to choose laws or regulations, how to configure resources, as long as the definition of property rights is clear, through negotiation and transaction, high efficiency of results always engender. In fact, there are transaction costs. Under this situation, the laws that can minimize transaction costs are the most appropriate. Impacts on transaction costs include actual transaction costs and low efficiency of selection which is to avoid the transaction costs [1]. The theory is "Coase theorem". On the basis of Coase theorem, environmental property, in practice, gradually formed "Coase means" with the representative of voluntary negotiation and property transacting. "Coase means" takes the total amounts of pollution controlling as a prerequisite, the transaction principles as a base, the feature of pursuing profits and avoiding disadvantages as the guide. Subjects of the rights (governments or management organizations) distribute or sell environmental property rights, buyers possess and use the environmental property achieved, get benefits from it and make the distribution in accordance with relevant regulations. "Coase means" formed the basic model of environmental property rights transacting.

China's environmental property rights transactions have been gradually carried out, but some constraints affect the efficiency and effects of environmental property transacting. Jin Shuai, Sheng Zhaohan, Du Jianguo (2013) argue that the initial distribution projects based on polluting resource inputs, economic output, and pollution emissions and other enterprises' relative performances 
have produced distortive incentives in different degrees and can lead to inefficient resource allocation and sub-optimal social output [2]. Wu Zhengfan, Xiang Xiaodong (2012) point out that for the transaction of pollution emission rights, relevant parties has piloted, but lots are related to the compensation policy, there is little caring for the total control of emissions trading. At the technical level of policy design, one of main factors causing this condition is the lack of effective initial distribution structure of pollution rights [3]. How to determine the initial prices of using emission rights and reflect the scarcity of environmental resources are disputed issues in practice. At present, the initial prices of compensable use of emission indexes in the pilot area are mainly decided by environmental protection institution, state administration of commodity prices, development and reform commission and other departments. In the initial distribution, the participation of enterprises is lower, which is also reason why the policy is hard to be conducted. Li Zhixue, Zhang Xiaojie (2015) think that at present, although some cities have piloted the transaction of emission rights in China, transaction data are relatively few, it can't form market-oriented mechanism. Actual transaction prices are lower than the treatment costs, which fails to reflect the scarcity of emission rights. Unified and complete market price mechanism is not formed. The transactions are influenced greatly by human, the fluctuation is bigger [4]. Xia Xiuyuan (2015) points out that the emissions trading system has a low cost and high efficiency, takes into account the protection of the ecological environment and the economic development, so it is adopted by countries. But, the successful implementation of emission rights transacting must rely on perfect laws and market mechanism. However, China doesn't have complete laws \& regulations, and market mechanism related to the transaction of emission rights, so its conduction is limited [5]. Wang Jiefang (2014) thinks that China's emissions trading market is not perfect, if there are huge differences between the initial distribution of emission rights and the existing emissions, enterprises can't adjust production methods or structure in time to adapt to it, at the same time, they can't buy necessary emission right on the market, economic and social development will be influenced badly. In the competitive mixed distribution mode of the initial emission rights, the proportion of the emission rights of competitive distribution depends on the "sensitivity" of economic and social development to the changes of emission quantity. The sensitivity is higher, the proportion of competitive distribution is smaller, and otherwise it is bigger. Meanwhile, according to the progress of the construction of the trading market, relevant parties can increase the proportion of distribution of competitive emission rights gradually, realize the dynamic distribution of emission rights in stages in this area, and achieve the goal of highly effective and fair distribution of emission rights [6].

The basic function of environmental property rights transacting is realizing the optimal allocation of environmental resources through market adjusting the production and operation activities of the subjects of transaction. From the 
perspective of resource optimization, the transaction of environmental property rights should be based on a unified trading market. Since 1999, China has introduced the transaction of emission rights form American environment protection association. Through constant development, China has got some experience in the transaction of environmental property rights with the representative of emission rights, but, generally, the bargain system based on the market is not established. In the regional market, there are different trading products, trading rules and management system, the markets are in lack of liquidity, therefore, it is hard to solve the transaction barriers caused by unknown transaction costs and differences of economic level of transaction subjects in the urban agglomerations and environmental capacity. Based on it, the study analyzes the transaction of environmental property rights in the urban agglomerations with an example of An-hui's cities along the river, explores its transaction paradigm.

\section{Basic Transaction Paradigm of Environmental Property Rights}

The transaction of environmental property rights promotes the development of theory that explains market-oriented transactions of environmental resources and relevant issues. To make the transaction more scientific and reasonable, it is necessary to establish a mature transaction system of environmental property rights that can reflect the relations correctly between transaction values and emission quota. Therefore, environmental property rights at this stage are mainly reflected in the transaction of environmental capacity resources, including carbon trading, emission rights trading and environmental permits transacting.

\subsection{The Paradigm of Traditional Carbon Trading}

Global warming becomes more and more serious; decreasing the emissions of global greenhouse gas is the key of environmental protection. The Kyoto Protocol, adopted in December 1997, introduced a carbon trading model to reduce the emissions of greenhouse gases with the representative of carbon dioxide-a transaction mechanism taking the emission rights of carbon dioxide as the object. From the view of the transacting model, carbon transactions mainly are divided into allowance-based transactions and voluntary transactions.

Countries or enterprises having compulsory emission reduction obligations, through carbon transacting platforms, realize the transaction of emission rights, which is called allowance-based transactions. This mechanism encourages these subjects of emissions save their emission limits and they can use the amounts that are saved to create values for themselves. At the same time, for those non-energy-saving subjects, if they exhaust all resources, they have to buy allowance from other subjects. The allowance transaction embodies the characteristics of economic incentives and stimulation.

Voluntary transactions are based on voluntary carbon market. Its basic model is that subjects of reducing emissions have the voluntary transactions to decrease 
the emissions. The emergence of voluntary carbon market is earlier than United Nations Framework Convention on Climate Change of 1992, Kyoto Protocol of 1997 and EU Emissions Trading System of 2005 (EU-ETS). In 1989, there was voluntary investment of the carbon capturing and sealing technologies (CCS), which is the first case in the voluntary carbon transactions. Voluntary transactions were once the main type of carbon trading, but the transaction subject have limited demands for emission-reduction products, voluntary markets lack mandatory capacity, this type of transaction is just a small part on the global carbon emission market. In 2009, voluntary carbon transactions accounted for about $1 \%$ of global total carbon transactions, and their transaction amounts (money) were just $0.27 \%$ of total amounts of global carbon trading. But, the potential of the voluntary carbon market is still huge. For example, the REDD + mechanism was put forward and put into practice at the end of the 1980s. After ten years, the cleaning development mechanism of Kyoto Protocol began to consider how to take the mechanism used to prevent the forest degradation into compulsory carbon market. This is an advantage of voluntary carbon market, can lead the direction of the development of carbon trading market.

\subsection{The Transaction Paradigm of Pollutants Discharging Rights}

The owners of environmental property rights set the pollution-discharging rights, allow the transaction of the discharging rights according to the market mechanism, thus relevant parties control the emissions of pollutants, which is called the transaction of pollutants-discharging rights. The transaction of pollutants-discharging rights combines administrative governance and market mechanism, its basic thought is ascertaining total emissions of pollutants firstly, secondly, have the reasonable distribution of discharging allowance, allow the subjects to choose the quantity of discharging. This means that the pollutants-discharging rights from these subjects having low treatment costs flow into those subjects having high treatment costs. At last, the goal of optimizing the effects of environmental governance is achieved.

The appearance of the transaction of pollutants-discharging rights makes people change their view to the environment. In the past, most people always hold the opinions that environmental pollutant-holding capacity is infinite. In fact, environmental pollutant-holding capacity depends on the nature world that is the material base of people's survival and development, has limits. Environmentalists and economists use the words-"safety valves" to define the limits of environmental pollutant-holding capacity. In the emission rights trading system, the environment is a property that reflects the properties of public goods, and its public capacity is stronger. Therefore, the ownership of environment should belong to the subjects who represent public benefits. In this transaction mode, the subjects representing public rights like governments will control total emissions in accordance with the "safety valves", then issue transaction licenses, distribute pollutants-discharging indexes through the primary market (sell at a certain 
price, auction, free distribution and other methods) to the subjects of pollutants discharging. After distributing the initial pollutants-discharging rights, relevant parties will decide whether to make the second transactions of emission rights according to the ability of controlling emission costs, demands of emission rights and other factors. In this process, market plays its role. Therefore, the transaction of emission rights becomes a highly effective mode of treating environmental pollution.

\subsection{The Transaction Paradigm of Environmental Licenses}

Environmental licenses trading system is a transacting mode of environmental property rights under the auction model. People who decrease the emissions of pollutants, through the auction licenses issued by governments or other departments, can sell emission allowances and get economic benefits from it. Thus, the purpose of environmental governance is achieved. This trading system is similar to the transaction of emission rights, but there are still differences. The operation mode of the later one is based on the total pollutants controlling, if actual emissions are lower than the allowances, the subjects can transfer after getting the approval. In this trading mode, allowances are distributed under the state of non-market. In the process, the subjects representing public benefits put the allowances on the market; they give the instruction, instead of participation. This is an external method to manage pollutants-discharging. Those who discharge pollutants can discharge only when they own licenses, but the licenses can be sold. According to this principle, subjects having the public rights are more like "the auction organization of environmental licenses". Firstly, it is required to evaluate the optimal emission level within the range of management; secondly, organizers need to ascertain the quantity of environmental licenses used for transactions; finally, organizers sell certain licenses through the auction, and provide that only the buyers who own the licenses can bring certain pollution. If optimal pollution level evaluated changes, managers can adjust by increasing or decreasing environmental licenses. It is necessary to point out that the optimal pollution level is not static, changes with natural environment, human society and many factors. So, the amounts of environmental licenses used for transaction should be adjusted. From this, it can be found that the auction organization of environmental licenses actually play the role of regulating the environmental pollutant-holding capacity. Specifically, it is like a market that controls the transactions of environmental licenses. Managers can use the market to adjust and control environmental pollution degree, and make it be in the optimal level.

The transaction system of environmental licenses is easy to be operated and conducted. In this process, relevant departments just need to ascertain the quantity of environmental licenses used in the transaction according to the optimal pollution level, then sell licenses by the auction, adjust the quantity of licenses in time according to the changes of the optimal pollution level. This method of regulating is practical, especially for solving these similar issues having external 
characteristics, as resources' depletion, ecological imbalance, etc. For example, to resolve the problem of water pollution in an area, managers can establish an auction organization to sell waste water discharging licenses. The organization can ascertain the optimal emissions according to the water quality in this area, and then determine the amounts of licenses, thirdly, have the transactions by the method of auction. At last, the purpose of controlling the emissions of waste water is achieved.

\section{The Transaction Paradigm of Environmental Property Rights in the Urban Agglomerations}

The synergistic development of urban agglomerations is the main direction of China's regional development strategy, and the coordination of ecological environment is an important part of it. Due to the differences of regional economic development level and environmental governance level in China, the use condition of environmental capacity is different. Usually, the undeveloped areas have poor environment treating base, high treatment costs, are hard to solve the issuethe use of environmental capacity. So, the transaction system of environmental property right taking the regions as the subjects of participation needs to be formed immediately. Urban agglomerations as a higher level of urban organization form have the transactions of environmental property rights among macro subjects on the base of the trading system of unified market, which can promote the coordinated development of ecological environment effectively. We plan to use models to analyze the transaction of emission rights of An-hui's cities along the rivers, explore basic paradigm of the transaction of environmental property rights in the urban agglomerations. The situation of environmental governance in Wan-jiang City Belt these years as shown from the Tables 1-6.

\subsection{Transaction Paradigm}

From the level of transactions, the transaction of environmental property rights in the urban agglomerations is consisted of primary transactions and secondary transactions. The primary trading market consists of the trading center of urban agglomerations, the transaction management center and the market subject. The

Table 1. General situation of environmental governance in An-hui (2011-2015).

\begin{tabular}{ccccc}
\hline Year & $\begin{array}{c}\text { Industrial } \\
\text { Waste-water (IW) } \\
\text { Discharges }(10 \mathrm{kt})\end{array}$ & $\begin{array}{c}\mathrm{SO}_{2} \text { Emissions } \\
(10 \mathrm{kt})\end{array}$ & $\begin{array}{c}\text { Comprehensive } \\
\text { Utilization Rate } \\
\text { of Industrial } \\
\text { Solid Waste }(\%)\end{array}$ & $\begin{array}{c}\text { Numbers of } \\
\text { Environmental } \\
\text { Emergencies }\end{array}$ \\
\hline 2011 & 70,720 & 48.72 & 78.70 & 12 \\
2012 & 67,175 & 46.98 & 81.50 & 20 \\
2013 & 70,972 & 45.02 & 83.99 & 6 \\
2014 & 69,580 & 44.06 & 84.44 & 8 \\
\hline
\end{tabular}


Table 2. Environmental survey of Wan-jiang city belt in 2011 .

\begin{tabular}{ccccc}
\hline Area & $\begin{array}{c}\text { Industrial } \\
\text { Waste-water } \\
(\mathrm{IW}) \text { Discharges } \\
(10 \mathrm{kt})\end{array}$ & $\begin{array}{c}\mathrm{SO}_{2} \text { Emissions } \\
(10 \mathrm{kt})\end{array}$ & $\begin{array}{c}\text { Comprehensive } \\
\text { Utilization Rate } \\
\text { of Industrial } \\
\text { Solid Waste (\%) }\end{array}$ & $\begin{array}{c}\text { Numbers of } \\
\text { Environmental } \\
\text { Emergencies }\end{array}$ \\
\hline Hefei & 6038.90 & 49,497 & 93.80 & 0 \\
Wuhu & 2690.74 & 36,289 & 84.48 & 0 \\
Maanshan & 7446.74 & 66,457 & 68.59 & 1 \\
Chuzhou & 3972.20 & 17,233 & 80.37 & 0 \\
Xuancheng & 4672.83 & 20,541 & 74.90 & 2 \\
Tongling & 4351.36 & 38,478 & 72.33 & 0 \\
Anqing & 4637.11 & 17,685 & 97.06 & 2 \\
Chizhou & 1571.54 & 16,561 & 74.30 & 0 \\
\hline
\end{tabular}

Table 3. Environmental survey of Wan-jiang city belt in 2012 .

\begin{tabular}{ccccc}
\hline Area & $\begin{array}{c}\text { Industrial } \\
\text { Waste-water } \\
(\mathrm{IW}) \text { Discharges } \\
(10 \mathrm{kt})\end{array}$ & $\begin{array}{c}\mathrm{SO}_{2} \text { Emissions } \\
(10 \mathrm{kt})\end{array}$ & $\begin{array}{c}\text { Comprehensive } \\
\text { Utilization Rate } \\
\text { of Industrial } \\
\text { Solid Waste } \%)\end{array}$ & $\begin{array}{c}\text { Numbers of } \\
\text { Environmental } \\
\text { Emergencies }\end{array}$ \\
Hefei & 5971.01 & 45,572 & 93.85 & 0 \\
Wuhu & 3147.62 & 36,789 & 95.67 & 1 \\
Maanshan & 6911.48 & 67,941 & 69.22 & 2 \\
Chuzhou & 5088.78 & 17,702 & 96.36 & 3 \\
Xuancheng & 4316.15 & 20,345 & 79.75 & 0 \\
Tongling & 5035.06 & 37,869 & 83.13 & 2 \\
Anqing & 4708.18 & 17,130 & 98.21 & 2 \\
Chizhou & 1459.19 & 16,017 & 70.48 & 2 \\
\hline
\end{tabular}

Table 4. Environmental survey of Wan-jiang city belt in 2013.

\begin{tabular}{ccccc}
\hline Area & $\begin{array}{c}\text { Industrial } \\
\text { Waste-water } \\
(\mathrm{IW}) \text { Discharges } \\
(10 \mathrm{kt})\end{array}$ & $\begin{array}{c}\mathrm{SO}_{2} \text { Emissions } \\
(10 \mathrm{kt})\end{array}$ & $\begin{array}{c}\text { Comprehensive } \\
\text { Utilization Rate } \\
\text { of Industrial } \\
\text { Solid Waste }(\%)\end{array}$ & $\begin{array}{c}\text { Numbers of } \\
\text { Environmental } \\
\text { Emergencies }\end{array}$ \\
Hefei & 6017.56 & $41,483.1$ & 93.16 & 0 \\
Wuhu & 3779.42 & $37,937.5$ & 96.66 & 1 \\
Maanshan & 6744.69 & $64,722.9$ & 70.21 & 0 \\
Chuzhou & 6459.91 & $18,522.0$ & 96.77 & 3 \\
Xuancheng & 5749.31 & $19,790.1$ & 83.97 & 0 \\
Tongling & 5653.64 & $36,888.6$ & 83.12 & 2 \\
Anqing & 4862.83 & $17,168.1$ & 96.87 & 2 \\
Chizhou & 2174.25 & $15,883.1$ & 80.21 & 2 \\
\hline
\end{tabular}

transactions of environmental property rights on this market are under the monitor of the government. Its operation mechanism is as the followings: 1) the 
Table 5. Environmental survey of Wan-jiang city belt in 2014 .

\begin{tabular}{ccccc}
\hline Area & $\begin{array}{c}\text { Industrial } \\
\text { Waste-water (IW) } \\
\text { Discharges (10 kt) }\end{array}$ & $\begin{array}{c}\mathrm{SO}_{2} \\
\text { Emissions } \\
(10 \mathrm{kt})\end{array}$ & $\begin{array}{c}\text { Comprehensive } \\
\text { Utilization Rate } \\
\text { of Industrial } \\
\text { Solid Waste (\%) }\end{array}$ & $\begin{array}{c}\text { Numbers of } \\
\text { Environmental } \\
\text { Emergencies }\end{array}$ \\
\hline Hefei & 6919.68 & $42,364.19$ & 92.91 & 1 \\
Wuhu & 3899.59 & $38,706.00$ & 93.32 & 0 \\
Maanshan & 7338.23 & $58,818.75$ & 71.06 & 0 \\
Chuzhou & 5755.26 & $20,525.30$ & 96.56 & 0 \\
Xuancheng & 3893.16 & $19,357.08$ & 85.18 & 0 \\
Tongling & 5692.98 & $31,435.60$ & 83.16 & 0 \\
Anqing & 4661.41 & $16,013.99$ & 96.54 & 3 \\
Chizhou & 2648.36 & $19,880.97$ & 74.92 & 0 \\
\hline
\end{tabular}

Table 6. Environmental survey of Wan-jiang city belt in 2015 .

\begin{tabular}{ccccc}
\hline Area & $\begin{array}{c}\text { Industrial } \\
\text { Waste-water (IW) } \\
\text { Discharges (10 kt) }\end{array}$ & $\begin{array}{c}\mathrm{SO}_{2} \\
\text { Emissions } \\
(10 \mathrm{kt})\end{array}$ & $\begin{array}{c}\text { Comprehensive } \\
\text { Utilization Rate } \\
\text { of Industrial } \\
\text { Solid Waste (\%) }\end{array}$ & $\begin{array}{c}\text { Numbers of } \\
\text { Environmental } \\
\text { Emergencies }\end{array}$ \\
\hline Hefei & 5334.98 & $40,828.7$ & 91.53 & 3 \\
Wuhu & 4933.27 & $38,064.1$ & 86.44 & 0 \\
Maanshan & 7694.53 & $48,713.4$ & 86.51 & 0 \\
Chuzhou & 5859.72 & $18,515.5$ & 96.36 & 0 \\
Xuancheng & 3664.98 & $19,195.4$ & 90.46 & 0 \\
Tongling & 5338.25 & $27,807.1$ & 90.58 & 3 \\
Anqing & 4469.63 & $14,738.1$ & 96.80 & 0 \\
Chizhou & 1422.11 & $17,344.9$ & 93.97 & 2 \\
\hline
\end{tabular}

Data from Anhui Statistical Yearbook 2012-2016.

trading center of urban agglomerations is in charge of transactions of environmental property rights, including registration, standards checking and confirmation, offer guidance in quoting, capital accounting, etc. At the same time, on the base of identifying the production, transactions, measurement standards, the trading center should make unified trading rules. 2) The trading management center is responsible for supervising and guiding in the transaction process, help the trading center to form the trading system with information symmetry, high transaction efficiency and fair price. 3) The market subjects, according to the trading rules, sell and buy environmental property rights.

As above contents, laws should confirm the ownership of environmental property rights firstly. After ascertaining the ownership of environmental property rights through the initial distribution of environmental property rights, the enterprises having more environmental property rights form the subjects of supplying, have the transactions with who have the demands. Environmental 
property rights have the nature of public goods, so the most outstanding feature of environmental resources is ecological environment, instead of property values. We should put out attention to its usage as public goods, rather than the use as private property. For the part having the property attribute, we should take public benefits and personal benefits into consideration, adopt top-down trading paradigm. "Top-down" here means that controllers can't let the supplying subjects carry out transactions with the other party who have the demands directly. In the transactions, subjects having public powers should supervise the transactions. Before the transactions, supervisors should check the qualifications of the two sides of the transaction and trading contents. In real trading process, market still play important role. The prices of trading are ascertained in accordance with the costs of marginal governance and situations of the market. For the supervision of transactions, because the transactions of urban agglomerations are hierarchical, in the primary trading market, the trading center of urban agglomerations can set trusteeship institutes. Firstly, supplying subjects store the surplus quota in the trusteeship institutes. Secondly, reserve institutes are in charge of checking and depositing. When the other party needs to buy quotes, they need to negotiate with the supplying subjects. After reaching a consensus, trusteeship institutes check and transfer the quotes to the demanding side. Any transactions without the participation of the trusteeship institutes are invalid.

After the establishment of a primary market, we intend to use the distributed hierarchical structure to set many secondary trading centers in accordance with gradation and districts in an environmental property rights trading market, form the secondary trading markets. All secondary trading centers give supports to complete the hierarchical transactions of environmental property rights, mainly are in charge of checking the environmental property rights used for secondary transactions, completing the delivering of environmental property rights. Through the cooperation of the two-tier trading institutions, we realize the optimized distribution of transacting objects in the whole urban agglomerations. The data declaration, settlement and management of the secondary market are the business of the secondary trading institutes. In the model selecting, the secondary trading is achieved mainly by transacting the environmental licenses. It means that on the basis of total amounts controlling, governments or other departments transfer environmental property rights by auction, realize the price balance in the process. This part, through establishing the transaction model of emissions rights of An-hui's cities along the rivers, analyzes that under the situation of restricting total emissions and how to make the reasonable distribution of environmental capacity by direct way or indirect way, researches basic paradigm of the transaction of environmental property rights in the urban agglomerations. The key issue is the relation between optimal trading amounts and the use of environmental capacity.

\subsection{Overall Environment Situations of Wan-Jiang City Belt}

"Wan-jiang" refers to the middle and lower parts of the Yangtze River. The parts 
are in the Anhui Province. Urban agglomerations in this area consist of Hefei (including Chaohu), Wuhu, Maanshan, Tongling, Anqing, Chizhou, Chuzhou, Xuancheng and other cities. There are 59 counties in total (city, district). On January $12^{\text {th }} 2010$, the State Council formally approved Wan-jiang city belt as a demonstration area to undertake industrial transferring. It is the only urban agglomeration that takes "industries transferring" as the theme. All are taken into "Yangtze River Delta" urban agglomeration. Environmental issues have obvious transitional, cumulative characteristics.

Hills and plains are main terrain condition of Wan-jiang city belt. There are bigger green areas in the cities, superior ecological basis. But the continuous improvement of industrialization and urbanization level, the rural population continues to come to the city, the urban spaces gradually expand, environmental problems are increasingly exposed, industrial pollution is more serious. The cities in Wan-jiang area take coals as the main consumption energy. So, air pollution is more serious. Air pollution source is from the soot. In the air, there are large amount of compound pollutants including nitrogen oxides, dusts, total suspended particulates, $\mathrm{SO}_{2}$ and others. With the increase of the consumption amounts of coals, contents of $\mathrm{SO}_{2}$ in the air increase. So, daily average concentration of $\mathrm{SO}_{2}$ in the urban agglomerations is near or over the limits of the secondary standards of national air quality. With the development of urbanization of the urban agglomeration, industrial waste water and domestic sewage are increasing, a large amount of sewage is discharged directly into rivers and lakes without the treatment and some water are polluted in different degrees. The industries discharging most pollutants include metallurgy, chemicals, paper manufacturing and others.

The ecological environment of Wan-jiang city belt becomes more and more serious. In order to effective environmental governance, the government of An-hui province conducted the paid use mechanism of emission rights and trading piloting mechanism in the Wan-jiang city belt, made Measures for the Control and Management of the Total Amount of Major Pollutants of Industrial Transferring Demonstration Zone that is undertaken by Wan-jiang city belt and Plans about the Paid Use and Trading Management of Emissions Rights of Industrial Transferring Demonstration Zone that is undertaken by Wan-jiang city belt, standardize the cognizance procedures, set platforms of emission rights trading.

\subsection{Relationship between Optimal Trading Volume and Environmental Capacity Utilization}

We are trying to seek the optimal transaction volume of environmental property rights of urban agglomerations, the environmental capacity in urban agglomerations and the net welfare relationship generated by the using of the environmental capacity of urban agglomerations through the establishment of a transaction model. In order to be convenient for the building of the model, the basic assumptions before modeling are as follows: 
1) The total emission of urban agglomeration is only restricted by the internal conditions of the urban agglomeration.

2) We will not consider the change of self purification ability over time; it is a constant during the transaction.

3) The total emissions of pollutants after the transaction shall not exceed the sum of the total amount of pollutants discharged by the main body involved in the transaction.

4) The environmental capacity of urban agglomeration before and after the transaction will be limited by the optimal utilization of urban resources.

Since the ultimate utility of the emissions trading is to keep the balance between the economic output of the transaction and the environmental governance effect, so it can be assumed that the social net welfare function under the emissions trading is a production and consumption function in single factor of pollutant under the condition that other factors remain unchanged, so the optimal allocation model of relationship between the total amount of pollutants and the direct consumption and indirect consumption of environmental capacity can be constructed.

Assuming that the urban agglomeration capacity is $C(C>0, d C=0)$, it can be divided into two parts, one is the environmental capacity that is not occupied directly but using environmental capacity $C_{i}\left(C_{i}>0\right)$ indirectly, and the other is the part $C_{d}\left(C_{d}>0\right)$ that occupied by the direct consumption of environmental capacity. Then in the case of self-purification capacity is a constant during the transactions, the net benefits arising from the utilization of environmental capacity of urban agglomeration is:

$$
N(C)=\xi N_{i}\left(C_{i}\right)^{\alpha} N_{d}\left(C_{d}\right)^{\beta}
$$

In the calculation, the elasticity coefficient is $\alpha+\beta=1, \alpha, \beta \geq 0, N_{i}$ is the benefits generated in the indirect consumption of environmental capacity, and $N_{d}$ is the benefits generated in the direct consumption of environmental capacity, at the same time:

$$
\begin{gathered}
N_{i}\left(C_{i}\right)=f\left(C_{i}\right)-u\left[p_{i} f\left(C_{i}\right)+\frac{p_{d}}{w} f\left(C_{i}\right)-C\right] \\
N_{d}\left(C_{d}\right)=C-C_{i}
\end{gathered}
$$

In this calculation, $f\left(C_{i}\right)$ is the production function of the indirect consumption of environmental capacity; $u$ is the unit cost of sewage disposal, $p_{d}, p_{i}$ respectively are the unit emissions in the process of direct and indirect consumption of environmental capacity, $u, p_{i}, p_{d} \geq 0, w$ is the ratio of total environmental capacity to consumption $(w \geq 0) ; \frac{p_{d}}{w} f\left(C_{i}\right), p_{i} f\left(C_{i}\right)$ is the total emissions generated from direct and indirect consumption of environmental capacity, so the total cost of urban sewage treatment is

$$
u\left[p_{i} f\left(C_{i}\right)+\frac{p_{d}}{w} f\left(C_{i}\right)-C\right] \text {. }
$$


Since $C_{i}, C_{d}$ is constrained by the optimal utilization of urban agglomeration resources, then:

$$
C_{d}=\frac{f\left(C_{i}\right)\left[1-u\left(p_{i}-\frac{p_{d}}{w}\right)\right](1-\alpha)}{f^{\prime}\left(C_{i}\right)\left[1-u\left(p_{i}-\frac{p_{d}}{w}\right)\right] \alpha+(\alpha-1) u}
$$

So, we can build the urban agglomeration pollutant discharge right trading model. Assume the trading volume is $a(a \geq 0)$, the transaction price is $b$ $(b \geq 0)$, the unit transaction fee is $c(c \geq 0)$, we will get the total effect of the transaction is:

$$
N(C+a)=\xi\left\{f\left(C_{i}+a\right)-u\left[f\left(C_{i}+a\right)\left(p_{i}+\frac{p_{d}}{w}\right)-C\right]-(c+b) a\right\}^{\alpha}\left(C_{d}-a\right)^{\beta}
$$

The first derivative of $a$ in this formula is available:

$$
b=\frac{1}{\alpha C_{d}-a}\left\{\left[f^{\prime}\left(C_{i}+a\right) d-c\right]\left(C_{d}-a\right) \alpha-\left[f\left(C_{i}+a\right) d-c a\right] \beta\right\}
$$

To simplify the result of the derivation, making:

$$
d=1-u\left(p_{i}-\frac{p_{d}}{w}\right)
$$

Therefore, the relationship between the optimal trading volume and the direct or indirect consumption of environmental capacity is:

$$
a=\min \left\{\alpha C_{d}, \frac{f^{\prime}\left(C_{i}+a\right) d C_{d} \alpha-f\left(C_{i}+a\right) d \beta}{f^{\prime}\left(C_{i}+a\right) d \alpha-c \beta}\right\}, C_{d} \neq a
$$

Assuming that all the polluters in the urban agglomeration are trading in emissions, in the general economic analysis, the market is in a clear state, so according to the balance of supply and demand in the trading market, the total amount of transactions must be zero. The following equation is established:

$$
\begin{aligned}
b & =\frac{1}{\alpha C_{d i}-a}\left\{\left[f^{\prime}\left(C_{i}+a\right) d_{i}-c_{i}\right]\left(C_{d}-a\right) \alpha_{i}-\left[f\left(C_{i}+a\right) d_{i}-c_{i} a_{i}\right] \beta_{i}\right\} ; \\
\sum_{i=1}^{n} a_{i} & =0, \text { in which, } i \in[1, n]
\end{aligned}
$$

From the scope of urban agglomerations, Wan-jiang city belt has Hefei (including Chaohu), Wuhu, Maanshan, Tongling, Anqing, Chizhou, Chuzhou, Xuancheng 8 cities in total to participate in the emissions trading, when $n=8$, there will be the optimal equation solution. It has a great practical significance to solve the contradiction between urban agglomeration development and environmental governance by introducing the trading mechanism of the city group emission right, and establishing the trading platform to realize the optimization of the utilization of the environmental capacity and to realize the maximum net welfare of the society. 


\section{Transaction Constraints Analysis}

Due to the characteristics of environmental property right is more complex compared to other property, so during the transaction, we should not only consider its property right attribute, but also should consider its attribute of public goods, so it is not only restricted by the inherent characteristics of the transactions of property rights, but also restricted by the restriction of environmental property rights characteristics. Through the above analysis model, the restriction factors of environmental property right transaction are embodied in the following aspects:

\subsection{Transaction Costs}

Excessive transaction costs have been the main problem of various types of environmental property rights transactions, which is related to the complexity of environmental property, rights itself. In contrast, the main body of environmental property rights is more complex, the boundaries of rights and responsibilities are difficult to be clarified, which directly leads to the high cost of its property rights; besides, during the process of defining, the data which is needed to rely is difficult to obtain, so that there is the problem of information asymmetry; design and post-regulation of the platform is also relatively difficult, all these links have become the factors of high transaction costs.

According to Coase, transaction costs refer to the costs of those jobs traded on the market (such as bargaining, contracting, supervision, etc.). In reality, for all products trading, as long as the market mechanism is running, there must be transaction costs, including the cost of defining and maintaining property rights, avoiding the costs of external costs and the input to maintain trust before the contract commitment of the parties. In these areas, any part has a situation of the high cost will significantly reduce the efficiency of the transaction. The Timothy \& Lata model illustrates the interaction between transaction costs and the efficiency of the transaction of pollutant permits. It has pointed out that the degree of transaction deviation will be reduced with the decrease of the marginal transaction cost. On the contrary, the high transaction costs will greatly reduce the effectiveness of the transaction [7].

It is precisely because the environmental property rights of the transaction cost content is rich and it is affected by many factors, even in country which has a more developed market and more perfect supporting system, the real role of environmental property rights transactions are also limited to the United States "Emission Reduction Credit" (ERC) trading, the Emissions Trading System of the European Union (EU-ETS) and other sporadic natural resources and emissions trading.

\subsection{Environmental Resource Characteristics}

Environmental resources mainly reflected as the ecological resources, which are based on the material basis of nature, it is essential to the survival and develop- 
ment of human being, it can help to built a common ecological system with human through the energy flow and material cycle.

As a kind of ecological resources, the natural environment has its integrity and self-regulation. First, the various components of the system constitute a complete system, no one can completely exclusive it, nor can do some exclusive consumption on it; secondly, the environmental resource system is a structural system which has self-renewal, self-recovery function, this system has a certain kind of adjust ability in a certain extent, it can compensate and buffer to the relatively small impact of the nature, so as to maintain its stability [8].

The overall nature of environmental resources is one of the main reasons why environmental resources embody the attributes of public goods. Under the constraint of this characteristic, the environmental resources are difficult to be effectively divided, which makes a difficult definition and disposition of their rights, including the definition of its property rights.

\subsection{Inherent Factors of Equity Transaction}

As a kind of equity transaction, environmental equity transaction must restricted by the inherent factors of equity transaction.

First of all, it will be subject to the transaction subject. According to the basic principles of economics, if the transaction subject is diversified, it can only increase the trading power, the varieties of subjects can play a different role in the transaction process. For example, if citizens and environmental organizations are the main body of the transaction, they can purchase emission rights without sewage in order to improve the ecological environment, so as to achieve the purpose of improvement; investors can get profit from the emissions trading, trading activity can have an effective protection in this mechanism. In fact, however, the main body of the transaction is often focused on large-scale industrial enterprises, the type of transaction is very simple under the restrictions of this situation, it is quite unfavorable for the vitality of transaction, the macroeconomic impact of the two sides is quite similar, changes in supply and demand will lack a kind of complementary effect, which results in the lack of motivation of trade.

Secondly, it is subject to the trading market. Generally believed that the full competition of the market needs a certain size, or it will be easy to form a monopoly, which will be difficult to achieve a full competition. At present, within a certain limit of the environmental property rights, the number of the participants is very limited; it is difficult to form an effective market competition and trade balance.

Thirdly, it is subject to the means of transaction. The auction is the main way of environmental property rights transactions, during the auction of property rights transactions, insiders transfer situation is very likely to occur. When the asset owner is listed on the auction (the tender), the transferee condition or information may be tilted to the insider, making it difficult to maximize the value 
of the asset, and causing the asset to "shrink". The parties may also conspire to cause the transferor to arbitrarily dispose of an important asset to a particular object and which will breed a serious transaction for corruption. Whether the value of the transaction can be achieved during the competition can also be limited by the results of the auction participation, participants, geographical and other issues.

\section{Conclusion and Discussion}

Through a certain kind of theoretical analysis and case deduction, it is not difficult to find that environmental property transactions are essentially a set of institutional construction and operation. From the current research and practice, the impact of relatively large factors to the scientific construction of the environmental trading system and its practice to produce improved results are mainly of macro transactions, the improvement of the construction of urban agglomeration platform, and the control of transaction costs and so on.

\subsection{Clear the Macro Transactions Subject of Environmental Property Rights}

The basic form of the environmental property right system is in the form of public property rights. In this property structure, the public is namely the proprietary of the environmental resources, but because individuals do not have a scale effect to practice this right, the decentralized rights will reduce the value of the rights due to the friction and conflict between the interests. The traditional view believes that weak property rights will lead an excessive use of resources. This is often because unclear property right is usually seen as an input exclusion problem - they are the resources which have been stolen or not extracted [9]. For this, the public need to pass on the environmental resources property rights to a macro trading subject which can be representative of the public interest and have scale effect of power exertion, this main subject will become the agent of the public to exercise the management of environmental resources, by its arrangement of the use and management of environmental resources, it will exclude all illegal violations of environmental resources. The environmental property rights of urban agglomerations are not only clearer relative to microcosmic subjects, but also can be easier to internalize external problems in urban agglomerations. Moreover, noticing the public and systemic characteristics of environmental resources, urban agglomeration of environmental property rights is easy to form a public trust relationship based on environmental resources.

Environmental Resources Public Trust Theory was first proposed by Professor Joseph. L. Sax of the University of Michigan in the USA, while the earliest public trust theory was originated from the Roman law. "Justification of Justinian Law" has pointed that: "According to the Natural Law, air, water, sea and coast are common to all mankind and are held by the king or the government through trust for the purposes of public interest and public use." [10], later on, the British 
common law create a public trust theory on the basis of this concept, pointing the king as a public trust property trustee.

In the United States, public trust theory was widely applied in the 1960s, such as the application of environmental factors as park land, inland lakes, swamps, wildlife, air, water and other natural resources. To the 1970s, legislation in some states broadened the scope of public trust theory to environmental protection, such as the Section 202 of the 1970 Environmental Protection Act of the Michigan, which takes air, water and other natural resources into the scope being protected by the principles of public trust theory, and confirms that citizens and other legal subjects have the right to sue for litigation on air, water and other resources of public trust [11]. Since the physical and non-separable nature of environmental resources respectively determined the positive external effects of environmental resources and the high cost of property rights, so the intervention of public property rights model is very important to solve this problem. The market mechanism based on discrete private rights can not match the characteristics of public goods of environmental resources, and the establishment of complete private property rights basing on the environmental resources is likely to be ineffective. Therefore, it is necessary to establish a public trust relationship of environmental resources and it should identify that the citizens and other legal subjects have the right to sue for litigation on air, water and other resources of public trust [12]. This is an effective means of further clarification of the subject of environmental property rights.

\subsection{Improve the Construction of Urban Agglomeration Trading Platform}

Because the object of environmental property rights often has the characteristics of public goods, its property is actually a fictitious right. In the transaction of fictitious property rights, the transaction cost is very huge, these costs include data collection, negotiation and consultation, supervision and management and so on, a perfect trading platform has played an irreplaceable role in reducing transaction costs, a platform which can bring together the information of traders and pollutants will have a great impact to emission trading, [13] especially in the trading rules, trading docking, transaction monitoring and transaction clearing, etc., but the function of trading platform also has a very high demand on its professionalism.

Professional trading platform and clear rules of the transaction can save both sides' costs in the transaction bargaining and contract development. The Chicago Climate Exchange has made specific rules on transaction types, trading forms, trading currency, contract changes, trading hours, trading price limits and liquidation, which have provided detailed rules and timely issuance of large amounts of information, and it has greatly promoted the smooth progress of the transaction. Therefore, the most important part of the construction of the transaction platform is to build a good information platform, if the degree of infor- 
mation disclosure is relatively low, the information is not timely, the information will be asymmetry or it will cause the operability of the transaction rules greatly reduced, and resulting in trade barriers. At this stage, the transaction participants should not only obtain the basic information of the transaction price from the trading platform, but also the important information such as the pricing of the whole market, the rules and the total amount of the emission rights index. However, the disclosure of such information is usually through a formal, rigorous process, information disclosure is in a more passive position, so it is essential to play the role of trading platform to enhance the initiative of information disclosure, so that the transaction participants can timely and accurate access the information, therefore, there must be an intermediate implementing agency to maximize the benefit of the beneficiaries of the transaction [14]. For example, for pollutant information, it can be published through the trading platform in a timely manner, and the pollutant information will have timeliness in a certain period of time, which can make the transaction participants generate a reasonable expectations under the guidance of the information, and to avoid information asymmetry, thus to enhance the quality of environmental property transactions of urban agglomerations. The international community has had previous case to use international organizations as platforms for environmental property trading, such as IMO (International Maritime Organization) to host ship carbon emissions trading; the global emissions trading system can also take a similar model [15].

\subsection{The Control of Transaction Cost}

In order to facilitate the discussion of the relationship between the actual use of environmental property right and the change of practice, when we construct this model, we assumed that the total amount of pollution in the urban agglomeration is only limited by the internal conditions of the urban agglomeration, and the change of self-purification capacity is not taken into account. However, it is necessary to ensure that the emission trading of urban agglomeration must related to the new system, so how to find a effective way to control the transaction costs under the new system is another prerequisite for the success of the transaction, while the most effective way to control transaction costs is to clarify property rights. According to the Coase theory, unclear property rights will lead to endless transaction costs. In the case of clear property rights, even if there is transaction cost, the main body of the transaction can not only use the form of transactions to solve their own problems, but also can maximize the total social welfare and minimize the transaction costs when the transaction is in a reasonable allocation of resources. Western countries can establish an environmental permit trading system under the guidance of the Coase theory, this system can achieve environmental property rights transactions in the case of small transaction costs, but this model is also based on the basis of clear property rights.

From a global perspective, through continuous practice of recent years, envi- 
ronmental property rights have been transformed from the traditional model to the modern model. And in China's various types of environmental property rights trading pilot, the type of environmental property used for trading is very simple, the difference between the costs of the transaction is limited, and it lacks of trading power under the impact of macroeconomic. So the establishment of a more complete environmental management information system is an effective way to effectively reduce transaction costs. In the course of the transaction, the price of the emission right, the demand supply situation, the relevant information of the transaction enterprise is very important to the smooth operation of the transaction. However, at present, the information disclosure mechanism in the process of environmental property rights transaction is not complete and it has converted into the credit problems and information accuracy problem in transaction. In addition to the information disclosure mechanism itself, the supporting supervision, reward and punishment mechanism design is also lagging behind. In the case of carbon trading, for the intergovernmental carbon trade, as a negotiator and a supervisor, the government cannot built a coordination and monitoring mechanism for its own transaction process, and it is also difficult to comply with the rules of the transaction as a participant. As for the carbon trading for private subject, the government sometimes also failed to play a coordinating and supervisory role. In terms of emissions trading, emissions trading has a higher demand for managers, after the establishment of emissions trading market, the Government is asked to implement a strict monitoring procedure, or no matter what kind of emission system design possibly will become a mere formality and cannot play a practical role. As for government monitoring work, it is to ensure the implementation of emissions trading from the macro point of view, specifically speaking, they should actually do the actual amount of emissions to monitor the registration of emissions trading, punish violations and so on.

In some countries, the environmental property rights trading mechanism has established a complete system of information disclosure in this aspect, and they have widely absorbed public participation in supervision, and introducing third-party supervision mechanism with a strict market order, which can be reference for us. Such as the "monitoring-reporting-verification" mechanism of the EU carbon trading market, it has a clear division of oversight responsibilities, monitoring, reporting and verification works are separated into steps: making procedures for monitoring and reporting, guiding the emission subject to complete the monitoring and reporting work in accordance with the procedures, and subsequent inspections shall be carried out by independent verification institutions and open to the public. The US sulfur dioxide trading market has established a sewage tracking system, the annual adjustment system and the licensing system three audit systems to monitor the sulfur dioxide trade, in addition to pre-monitoring mechanism, there is supporting system after the implementation, such regulatory mechanism has achieved positive and significant results to the United States Emissions trading.

In addition to the above-mentioned system construction, the introduction of 
diversified subject, the improvement of the transaction participation, strengthen of the value assessment also played a very important role to prevent the fraud in the transaction mode of environmental property rights trading system optimization. As the environmental resources have a strong public property attributes, it covers a large number of content and has strong externalities, which bring some difficulties to explore the trading mechanism, aiming for this difficult, we will further improve the research methods and explore the internal relations between the definition of property rights and the theory of trade, and making more scientific and practical mechanism design basing on this, to explore the mechanism to build an effective way to optimize.

\section{References}

[1] Posner, R.A. (2014) Economic Analysis of Law. 9th Edition, Wolters Kluwer Law \& Business.

[2] Jin, S., Sheng, Z. and Du, J. (2013) On the Construction of Initial Allowances Allocation Mechanism in Transitional Period: Incentive Analysis and Optimal Design. China Population, Resources and Environment, No. 2, 48-56.

[3] Wu, Z. and Xiang, X. (2012) A Design Framework for Initial Allocation of Emission Rights. Environmental Science \& Technology, No. 1, 201-205.

[4] Li, Z. and Zhang, X. (2015) Carbon Emissions Initial Allocation Method and Problem Analysis. Environmental Engineering, No. 1, 150-153.

[5] Xia, X. (2015) Reflections on the Emission Trading in the Ecological Environment Protection in China. Ecological Economy, No. 7, 144-147.

[6] Wang, J. (2014) Competitive Decision Method of the Initial Emission Rights Allocation under Total Quantity Control. China Population, Resources and Environment, No. 5, 88-92.

[7] Cason, T.N. and Gangadharan, L. (2003) Transactions Costs in Tradable Permit Markets: An Experimental Study of Pollution Market Designs. Journal of Regulatory Economics, 23.

[8] Lv, Z. (2000) On the Trading System of Environmental Rights. Tribune of Political Science and Law.

[9] Hotte, L., McFerrin, R. and Wills, D. (2011) On the Dual Nature of Weak Property Rights. Resource and Energy Economics, 35, 659-678.

[10] Zhang, Y. (2011) The American Environmental Public Trust Theory and the Environmental Protection Mechanism for China's Enlightenment. Political Science and Law.

[11] Roogers, W.H. (1994) Environmental Law. West Group, 172-173.

[12] Cai, S. (2002) On Environmental Rights. Jin Ling Law Review, 83-119.

[13] Tao, W., Zhou, B., Barron, W.F. and Yang, W. (2000) Tradable Discharge Permit System for Water Pollution-Case of the Upper Nanpan River of China. Environmental and Resource Economics.

[14] Ambec, S. and Hotte, L. (2006) On the Redistributive Impact of Privatizing a Resource under Imperfect Enforcement. Environment and Development Economics, No. 11, 677-696. https://doi.org/10.1017/S1355770X06003214

[15] Hermeling, C., Klement, J.H., Koesler, S., Köhler, J. and Klement, D. (2015) Sailing into a Dilemma: An Economic and Legal Analysis of an EU Trading Scheme for Maritime Emissions. Transportation Research, No. 7, 34-53. 
Submit or recommend next manuscript to SCIRP and we will provide best service for you:

Accepting pre-submission inquiries through Email, Facebook, LinkedIn, Twitter, etc. A wide selection of journals (inclusive of 9 subjects, more than 200 journals)

Providing 24-hour high-quality service

User-friendly online submission system

Fair and swift peer-review system

Efficient typesetting and proofreading procedure

Display of the result of downloads and visits, as well as the number of cited articles Maximum dissemination of your research work

Submit your manuscript at: http://papersubmission.scirp.org/

Or contact gep@scirp.org 